\title{
Effect of an organoclay on the reaction-induced phase-separation in a dynamically asymmetric epoxy/PCL system
}

\author{
J. Rotrekl, A. Sikora, L. Kaprálková, J. Dybal, I. Kelnar* \\ Institute of Macromolecular Chemistry, Academy of Sciences of the Czech Republic, Heyrovsky Sq. 2, 16206 Prague, \\ Czech Republic
}

Received 13 June 2013; accepted in revised form 23 August 2013

\begin{abstract}
The addition of layered silicates can significantly affect the phase behaviour of both immiscible thermoplastic blends and partially miscible thermoset systems that undergo reaction-induced phase separation (RIPS) during curing. This study focuses on the phase behaviour of polycaprolactone (PCL)/epoxy in the presence of organically modified montmorillonite (oMMT). Due to the high dynamic asymmetry caused by the differences in the molecular weights and viscosities of the PCL and the uncured epoxy, the critical point is localised at low PCL concentrations, as indicated by the pseudophase diagram. The addition of oMMT to the system led to the marked shift of the critical point towards higher concentrations of PCL, with an increase in the oMMT content occurring as a consequence of the preferential localisation of the clay in the epoxy phase, making this phase more dynamically slow. Significant changes in morphology, including phase inversion of the PCL/epoxy systems caused by the presence of oMMT, were recorded for PCL concentrations ranging from 10 to $30 \%$.
\end{abstract}

Keywords: nanocomposites, epoxy, microstructure, reaction induced phase separation

\section{Introduction}

Epoxies are often used in combination with liquid rubbers or thermoplastic polymers [1-4] to reduce their brittleness. An effective two phase structure [5] can be obtained by the reaction-induced phase separation (RIPS) of the initially dissolved polymeric modifiers. Recently it was found that behaviour of multicomponent polymer systems can be significantly altered by using nanofillers. The presence of nanofillers in polymeric mixtures can affect the thermodynamics of its phase behaviour, the kinetics of phase separation, and also the morphology formed in the two-phase region [6-14]. Bousmina et al $[15,16]$ found in PS/PVME blend that organoclay changed the mechanism of phase separation from spinodal decomposition to nucleation and growth and affected the final morphology obtained after phase segregation. Organoclay represents an efficient active interfacial agent that enlarges the miscibility window and reduces the size of PS droplets. Theoretical study of Balazs et al. [17] showed that preferential wetting of nanofiller by one of the polymers may slow down the kinetics of spinodal decomposition. As a result, nanoparticle addition to binary mixtures could decrease the rate of domain growth and leads to a pinning effect on interface motions. The fact that the addition of nanoparticles could diminish the diffusion of polymeric chains and retard the phase separation was confirmed experimentally $[10,12]$. The effect of the nanofiller on the phase behaviour can be controlled by altering the polymer clay affinity using various clay modifications, leading to the preferential wetting of one component of the blend [18].

\footnotetext{
${ }^{*}$ Corresponding author, e-mail: kelnar@imc.cas.cz

(C) BME-PT
} 
In the case of partially miscible thermoset systems, the clay influences the RIPS not only through a nucleating effect [19] combined with hindering the mass transport of the system but also by affecting the cure kinetics [20, 21]. The final phase separated morphology of the thermoplastic/epoxy mixture is also determined by its composition and cure temperature. The classic example of a thermoplasticthermosetting mixture is an epoxy alloy, in which the toughness has been modified through blending with high performance thermoplastics, such as poly (ether imide) (PEI), poly(ether sulphone) (PES), poly (phenylene ether) (PPE), polysulphone, poly(ether ketone) (PEK) and others. It has been reported that significant increase in toughness is [22] achieved only when the thermoplastics form a continuous phase in the mixture. Due to the importance of RIPS in determining the structure type and dimensions, including the composition of the respective phases, efforts to control the phase behaviour and morphology have attracted considerable interest. Curing of the epoxy-monomer containing a dissolved polymeric modifier leads to phase separation. This occurs depending on the composition of the reaction mixtures, either by a spinodal (SD) or a nucleation and growth (NG) mechanism. The resulting morphology is determined by the thermodynamic conditions of the phase separation [23] and by the viscoelastic characteristics of the separating phases [24-27]. These factors are particularly important in thermoplastic/epoxy mixtures that exhibit significant dynamical asymmetry due to large differences in the molecular weights and glass transition temperatures $\left(T_{\mathrm{g}}\right)$ of the two components [27].

Studies of the mechanisms of phase separation have revealed that the majority of polymer blends do not meet the implicit assumptions contained in the model for the phase separation of low-molecular weight liquid mixtures [25], which states that the viscoelastic properties of the components are similar to each other (i.e., symmetrical). As a general rule, the viscoelastic properties of the constituent polymer blends vary significantly due to differences in the size of the molecules and their flexibility. These systems are referred to as dynamically asymmetric, and their phase separation is considered viscoelastic phase-separation (VPS) [25]. It is important to note that the initiation of phase separation crucially depends on thermodynamic condi- tions. The viscoelastic properties of the components influence the phase separation mechanism once the system reaches thermodynamic instability. Tanaka's comprehensive model analysing the phase separation of binary polymeric mixtures [25] has defined the dynamic area under binodal in which the separation mechanism is controlled by bulk and shear stress. This regime is defined by the dynamic spinodal curve, in which the maximum temperature is lower than the upper critical solution temperature. In the concentration range in which the ratio of the components is close to 1 , phase inversion occurs.

As a result, the epoxy-rich phase tends to interfere even at the very early stages of SD due to its low viscosity and/or poor fluid strength. The minority phase, namely the thermoplastic-rich phase, is continuous due to its strengthened viscoelasticity during phase separation.

In our recent work [28, 29] we showed that nanoclay can significantly affect the behaviour of epoxy/ PCL systems containing 5-30\% PCL. The radical morphological transformations consisting of phase inversion for $20 \%$ PCL content due to increasing clay content led to a substantial improvement of the mechanical behaviour. The main reason for this phenomenon was a shift in the dynamic asymmetry caused by the localization of clay inside the epoxy phase, supporting its continuity. The results indicate the potential of clay to tailor the structure and properties of RIPS systems with significant dynamic asymmetry.

The aim of this study was to evaluate the influence of nanofillers on the phase separation behaviour represented by pseudophase diagrams in the whole concentration range of epoxy/PCL system and coresponding final morphology of nanocomposites.

\section{Experimental}

\subsection{Materials}

Organically modified montmorillonite Cloisite C30B (C30) with methyl tallow bis(2-hydroxyethyl) quaternary ammonium chloride was obtained from Southern Clay Products, Inc. (Gonzales, Texas, USA). Polycaprolactone (PCL) m.w. 40000 was obtained from Perstorp (Perstorp, Sweden). The diglycidyl ether of bisphenol A (DGEBA)-based epoxy resin, Epilox A19-02 (epoxy equivalent weight 185-200 g, m.w. $396 \mathrm{~g} / \mathrm{mol}$ ), was purchased from Leuna-Harze GmbH (Leuna, Germany), and the 
amine hardener diaminodiphenyl sulphone (DDS) was purchased from Aldrich (St. Louis, Missouri, USA).

\subsection{Preparation of blends and related nanocomposites}

The mixtures of epoxy, curing agent, PCL and oMMT were prepared by dissolving the components in tetrahydrofuran for 12 hours. The concentration of solution prepared was approximately $10 \%$. The solvent was removed under vacuum at room temperature for 48 hours. Thin layer samples for optical microscopy were prepared by insertion of small piece of material between two round glass plates (12 $\mathrm{mm}$ in diameter) and subsequent compression at $120^{\circ} \mathrm{C}$ to achieve thin layer $(\sim 50 \mu \mathrm{m})$.

\subsection{Cloud point evaluation and morphological observations}

The cloud point time was evaluated by the in situ optical microscopy observation of a thin layer $(\sim 50 \mu \mathrm{m})$ of sample sandwiched between two glass slides at $170^{\circ} \mathrm{C}$. A Linkam hot stage was used to heat the samples. In situ optical microscopy was also used for morphological observations. Pseudophase diagrams were constructed using conversion at the time of cloud point evaluated by FTIR measurement of samples heated at $170^{\circ} \mathrm{C}$ and quenched after reaching of cloud point time. Due to extremely slow curing rate of DDS at ambient temperature, the error can be neglected.

\subsection{Chemorheological measurements}

Chemorheological experiments were conducted using an ARES apparatus (Rheometric Scientific, Piscataway, NJ). The evolution of the dynamic viscosity and $\tan \delta$ during curing at $170^{\circ} \mathrm{C}$ were conducted in the parallel-plate geometry using an oscillatory shear deformation at a frequency of $6.28 \mathrm{rad} / \mathrm{s}$ $(1 \mathrm{~Hz})$ (estimated variation coefficient of viscosity at gel point is $5 \%$ ). Gelation time evaluation was based on $\tan \delta$, since gelation occurs at approximately $\tan \delta=1$, where loss modulus is equal to storage modulus [30].

\section{Results and discussion}

\subsection{Effect of clay on the curing reaction}

Chemorheological measurements were performed to evaluate the effect of clay on the viscosity and cure kinetics of the composites. Figure 1 illustrates

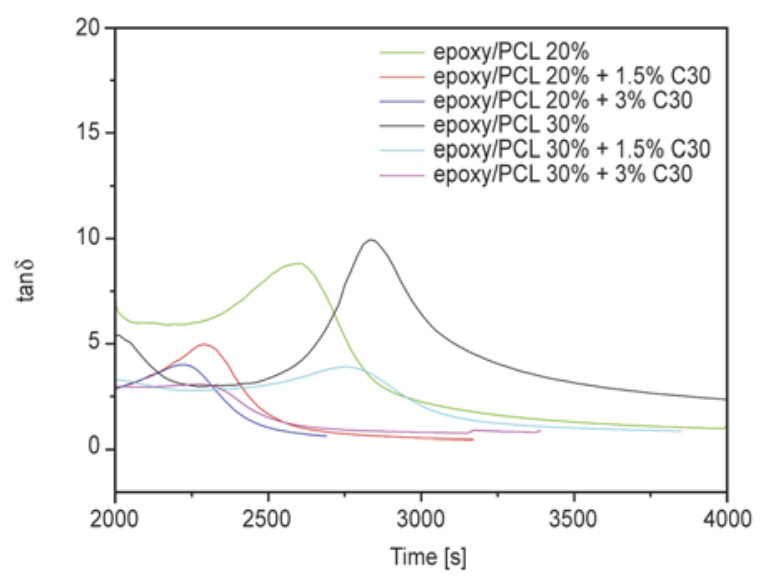

Figure 1. The evolution of $\tan \delta$ with curing time, as evaluated by chemorheology

the significant shortening of the gelation time $(\tan \delta=$ $1[30]$ ) and corresponding increase in reaction rate with increasing clay concentration, which has been observed previously elsewhere $[20,21,31,32]$. The increased reaction rate can be attributed to the catalytic activity of the ternary ammonium salt contained in the organic clay modifier on the epoxy amine reaction [33]. This effect is more pronounced with increasing oMMT content [31,32]. The quarternary ammonium salt also initiates the self-polymerisation of epoxy groups at elevated temperatures [34], which may contribute to the increase in the epoxy conversion rate. This hypothesis was confirmed by the $10 \%$ conversion observed by IR measurement of the blank sample, which contained the epoxy resin with added clay but no curing agent. However, there is no evidence that the PCL can participate in the reaction with epoxy, as demonstrated by the IR-based evaluation of the conversion of samples composed of epoxy and PCL only. Therefore, the PCL only affects the reaction rate through its contribution to the dilution of the reaction components, which results in prolonged reaction times. Figure 1 also reveals peaks in $\tan \delta$ corresponding to the onset of phase separation [35]. These peaks are in general agreement with the cloud point determined by in situ optical microscopy.

Chemorheological measurements provided further evidence of the effect of clay on the viscosity (Figure 2). The slight increase of viscosity at $2000 \mathrm{~s}$ for sample without oMMT coresponds obviously with phase separation [36]. The absence of this fluctuation for the sample containing oMMT most probably indicates the affecting of phase separation process by relative high content (3\%) of oMMT. 


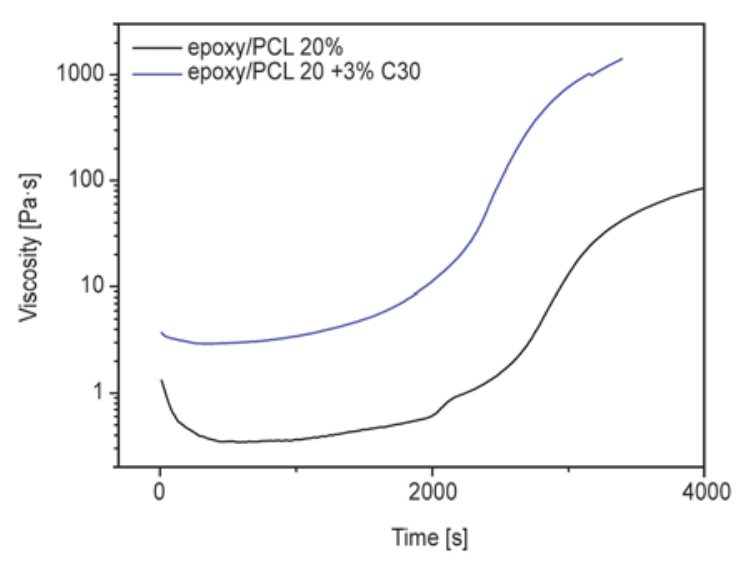

Figure 2. The evolution of viscosity with curing time, as evaluated by chemorheology

\subsection{Effect of clay on pseudophase diagrams}

The phase diagrams of the PCL/epoxy systems (Figures 3 and 4) reveal a minimum (critical point, $\mathrm{CP}$ ) located at approximately 10\% PCL content. This behaviour arises due to the dynamic asymmetry between the components due to their differences in molecular weight; in cases in which the two components exhibit similar molar masses, the critical point is $\mathrm{CP}=0.5$ and the phase diagram is symmetrical. The addition of oMMT led to a shift of the CP to higher concentrations of PCL. Due to the preferential concentration of the nanofillers with a high molar mass in the epoxy phase (documented by TEM in ref. [28], not shown), an increase in the apparent molar mass of the epoxy phase and a change in the effective (medium) interaction parameter occurred. As a result, the CP of the phase diagram shifted with increasing filler content to higher PCL content, in agreement with the Ginzburg model calculations [37].

From both the time- and conversion-based phase diagrams in Figures 3 and 4, it is evident that the time needed to achieve phase separation at a given curing temperature at high PCL concentrations decreased sharply with increasing filler content and that the conversion approached $100 \%$. This behaviour was influenced by several factors, including curing temperature. By temperature jump from room temperature to the curing temperature the studied mixture, gets into different depths of phase unstable area based on its composition. At low concentrations of PCL in the vicinity of the $\mathrm{CP}$, penetration to a completely unstable spinodal region takes place, leading to a rapid separation of the two phases throughout the sample volume. This behaviour sug-
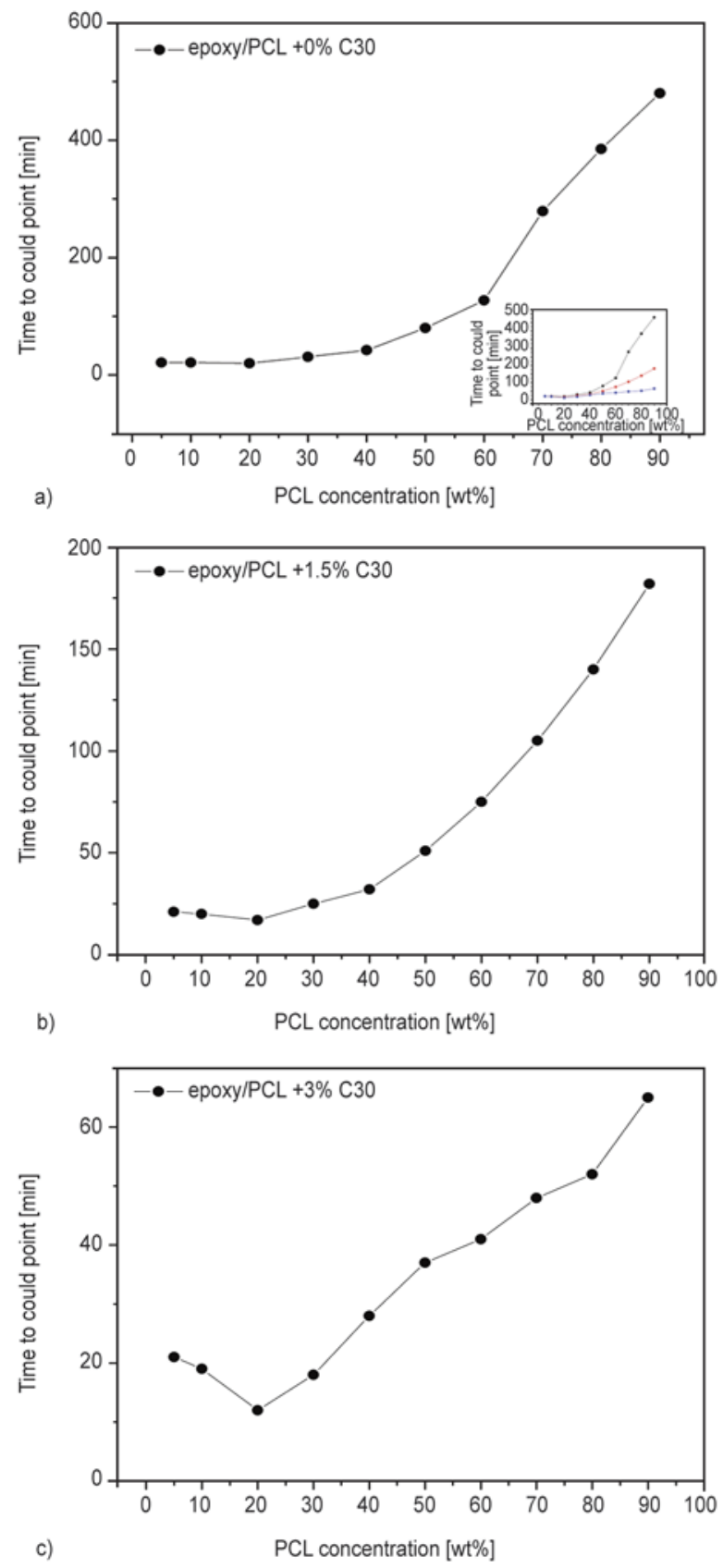

Figure 3. The effect of clay on the phase diagram of the time to cloud point vs weight fraction of PCL, (a) $0 \% \mathrm{C} 30$, (b) $1.5 \% \mathrm{C} 30$, (c) $3 \% \mathrm{C} 30$. Note significant differences in time to cloud point as indicated in the inlet picture.

gests that at low PCL concentrations a fast decay phase and brief turbidity occur, which are only slightly dependent on the filler content. At concentrations above $50 \%$ PCL, the depth of penetration into the unstable area of the phase diagram is lower and the system is located in the region between the spinodal and binodal curves, where phase-separation via nucleation and growth (NG) takes place. Development of the separated phase occurs in sepa- 


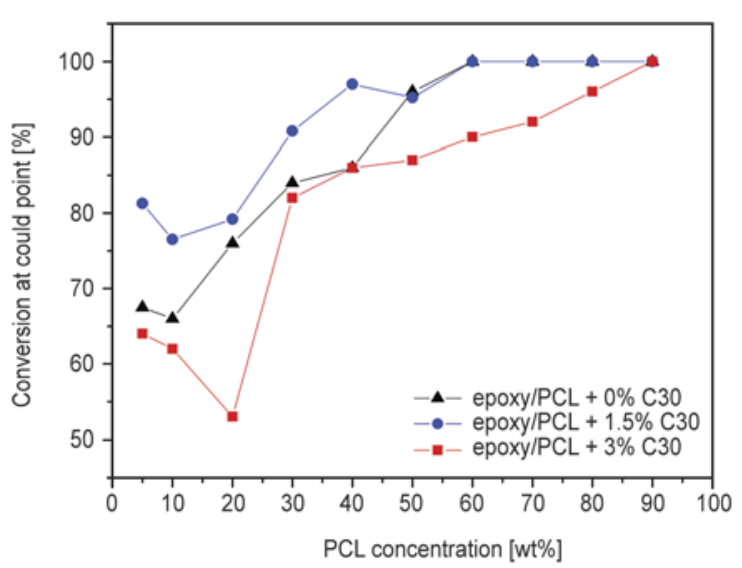

Figure 4. The effect of clay on the phase diagram of conversion at cloud point vs weight fraction of PCL

rate random domains relatively slowly. The time required for the emergence of an observable phase is extended, and as a result, the conversion detected during the initial phase separation is remarkably high. The decreasing time necessary to achieve phase separation with increasing filler content is in agreement with the observation that nanofillers accelerate epoxy curing. However, nano-sheets of MMT substantially restrict the diffusion of the system components, resulting in lower conversions at the threshold of phase separation, as depicted in the comparison of the phase diagrams in Figure 4.

This behaviour is in agreement with previously published data. When studying the phase behaviour of aqueous solutions of poly(vinylmethyl ether) (PVME), Tanaka observed unexpected morphological changes during phase separation at temperatures above the lower critical solution temperature (LCST) [24]. The resulting structure differed from the bicontinual phase structure with a subsequent phase separation(s) into domains, as described in the classical model of spinodal disintegration (SP) or the nucleation and growth mechanism (NG). Similar morphological changes have been observed in a wide variety of polymer blends, including inversion stages, which cannot be explained simply using the classical SD or NG mechanism [26, 38].

From Figure 5, it is apparent that the addition of 3\% filler to the mixtures containing 15 and $20 \%$ PCL led to phase inversion; the continuous PCL structure separated to form a domain structure. This can be explained by the influence of the filler on the effective interaction parameter and reaction rate. Both of these parameters shift the critical temperature (e.g., upper critical solution temperature to higher temperatures and higher concentrations of PCL; LCST to lower temperatures and higher concentrations of PCL). The dynamic spinodal curve shifted in the same direction as the areas of phase inversion. The addition of fillers caused the mixture to shift to this region of the phase diagram earlier than the binary mixture of PCL with epoxy. The addition of nanofillers also affected the viscoelastic behaviour of the epoxy phase, in which they preferentially concentrate. This altered the dynamic asymmetry of the mixture and extended the area of the inverted phases.

\subsection{Morphology}

The images captured using in-situ optical microscopy revealed a change in the morphology of the cured samples upon the addition of the nanoclay. At 15\% and $20 \%$ PCL content, the addition of $3 \%$ clay transformed the original structure, consisting of rough bi-continuous domains, into a structure comprising an epoxy matrix and fine PCL inclusions. The localisation of PCL was confirmed by the observation of PCL spherulites under polarised light. At higher PCL concentrations (over 20\%), the original spherical domains of the epoxy were converted to larger, irregular 'islands' as a consequence of the improved continuity of the epoxy and the change in asymmetry induced by the clay. The morphology may have also been affected by the change in reaction kinetics induced by the clay (Figures 1 and 2), which can lead to changes in the time interval (between cloud and gel point) available for phase separation [39]. The reduced time available for the development of the phase during curing was also confirmed by chemorheological measurements (Figure 1), which revealed a peak in $\tan \delta$ corresponding to the initiation of phase separation [40] that was closer to the gelation at higher clay concentrations. Furthermore, the $T_{\mathrm{g}}$ values demonstrate that, contrary to the increase observed in the neat epoxy nanocomposite, the $T_{\mathrm{g}}$ decreased with increasing clay content in the epoxy/ PCL [28]. This behaviour can be attributed to the incomplete phase separation caused by the accelerated curing and reduced diffusion (pinning effect) induced by the clay, which resulted in a higher concentration of 'dissolved' PCL in the epoxy rich phase. Thus, the phase separation freezes at an earlier stage in the presence of the clay.

The optical microscopy observations of thin layers of the material were in good agreement with the 


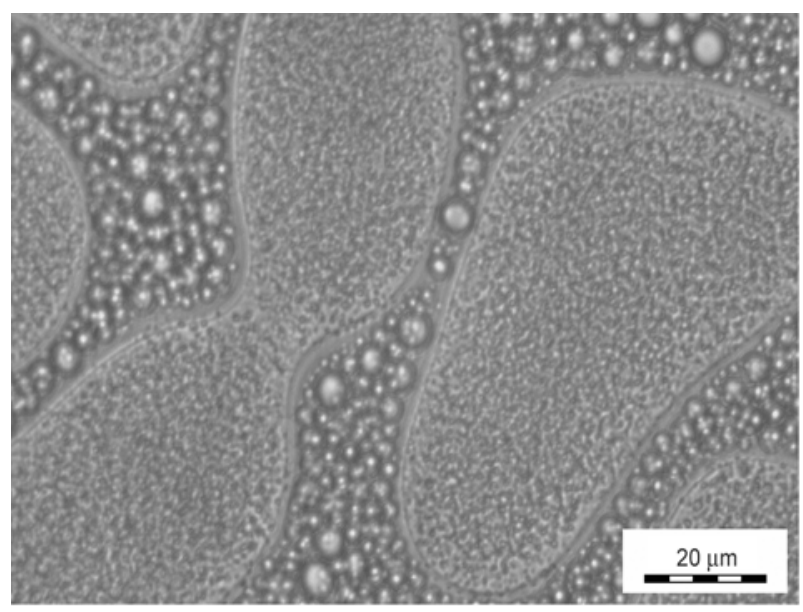

a)

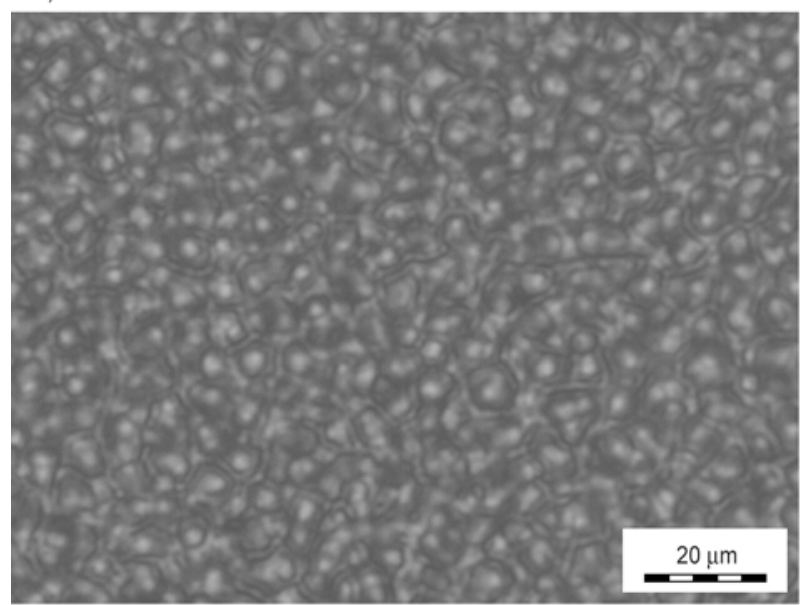

c)

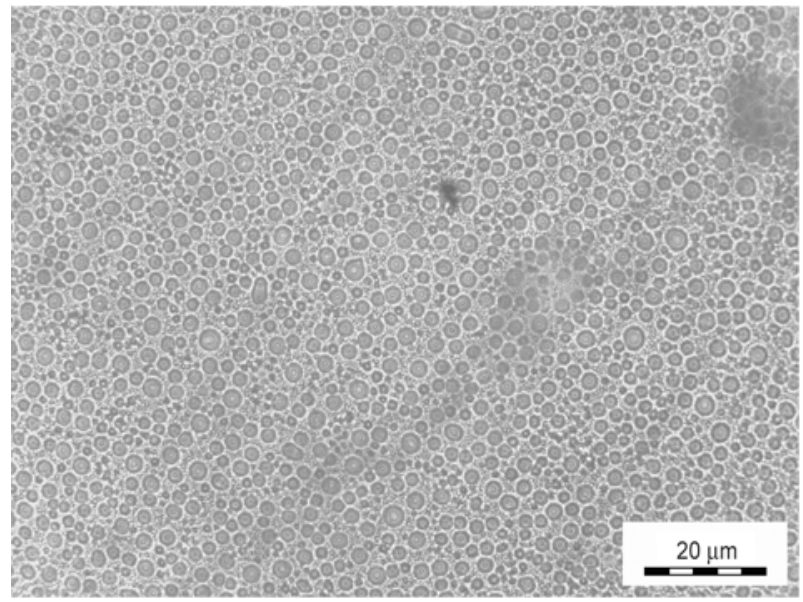

e)

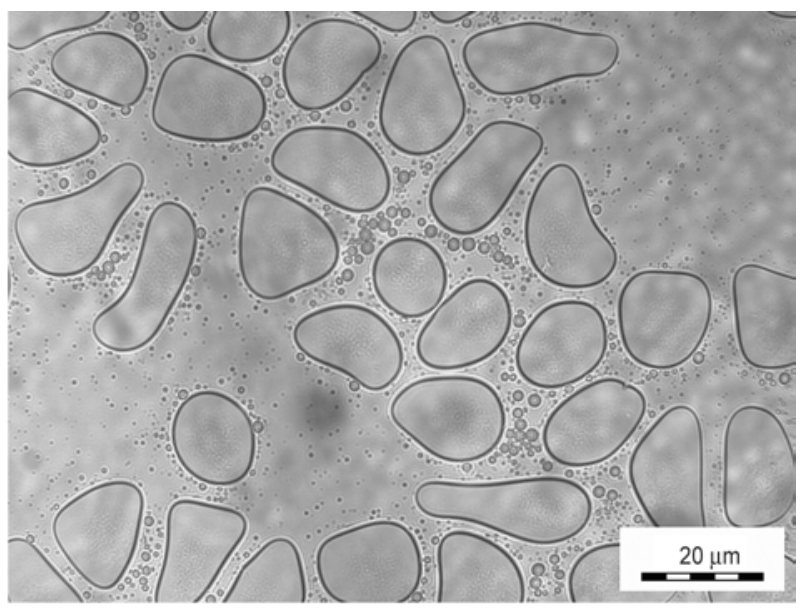

b)

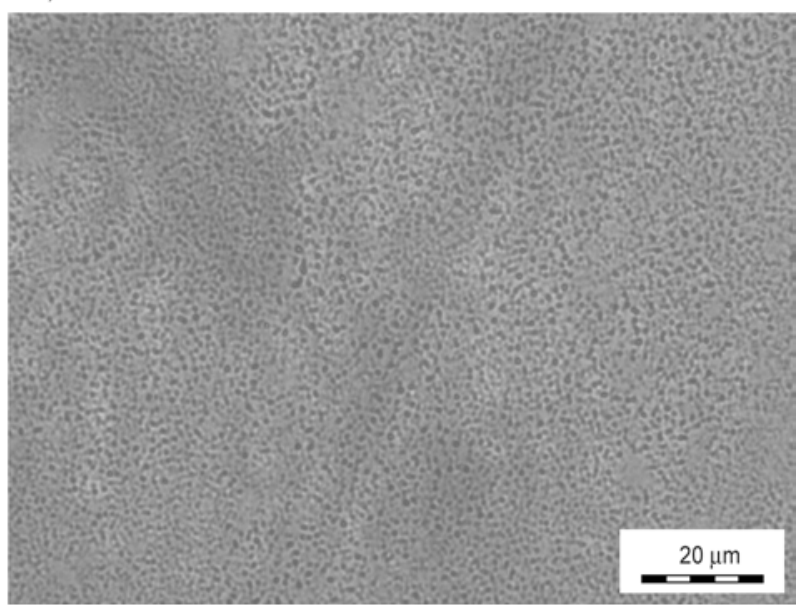

d)

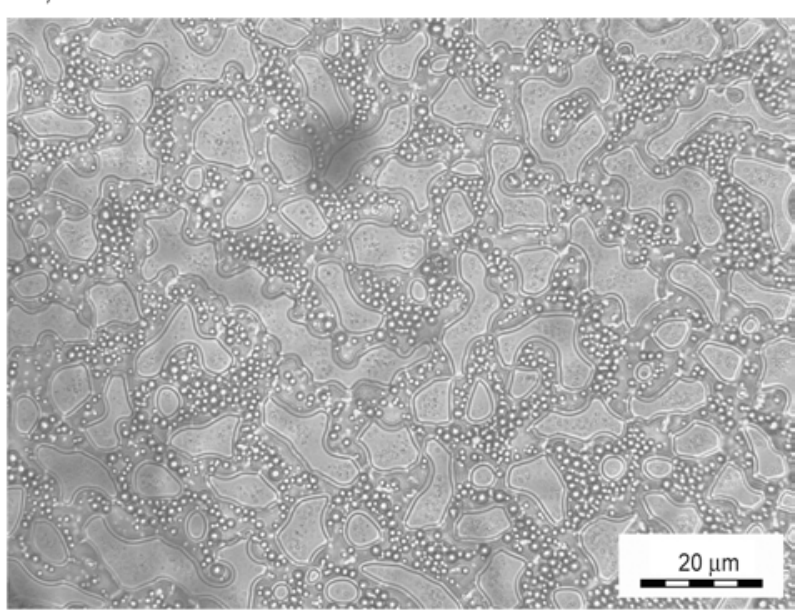

Figure 5. Morphology of thin layer samples observed by optical microscopy (a) $5 \%$ PCL, (b) $20 \%$ PCL, (c) $30 \%$ PCL (d) $15 \% \mathrm{PCL}+\mathrm{C} 30 \mathrm{~B}$, (e) $20 \% \mathrm{PCL}+\mathrm{C} 30 \mathrm{~B}$, (f) $30 \% \mathrm{PCL}+\mathrm{C} 30 \mathrm{~B}$

SEM observations [28] of bulk samples, which displayed phase inversion from a continuous PCL-rich phase with large epoxy globules to an epoxy-rich matrix with fine PCL inclusions with increasing content of clay.

\section{Conclusions}

The pseudophase diagrams of dynamically asymmetric PCL/epoxy systems with various clay contents demonstrated the marked ability of oMMT nanoplatelets to influence LCST phase separation 
behaviour. This is reflected most notably in the shift of the critical point towards higher PCL concentrations. Such behaviour can be attributed to the preferential localisation of the clay in the epoxy-rich phase, which slows its dynamics and results in a significant transformation in the morphology of cured blends at PCL concentrations near and above the critical concentration of the neat blend, including inversion from a PCL-rich matrix with globules of epoxy to an epoxy-rich matrix with fine PCL inclusions. The strong potential of nanofillers to alter the morphology of cured blends with a fixed content of polymeric modifier can be used to tailor the structures of multiphase thermosets.

\section{Acknowledgements}

This work was supported by the Grant Agency of the Academy of Sciences of the Czech Republic (project No IAA200500904)

\section{References}

[1] Francis B., Ramaswamy R., Rao V. L., Thomas S.: Toughening of diglycidyl ether of bisphenol-A epoxy resin using poly (ether ether ketone) with pendent ditert-butyl groups. International Journal of Polymeric Materials, 55, 681-702 (2006).

DOI: $10.1080 / 00914030500323326$

[2] Mimura K., Ito H., Fujioka H.: Improvement of thermal and mechanical properties by control of morphologies in PES-modified epoxy resins. Polymer, 41, 44514459 (2000).

DOI: 10.1016/S0032-3861(99)00700-4

[3] Bucknall C. B., Gilbert A. H.: Toughening tetrafunctional epoxy resins using polyetherimide. Polymer, 30, 213-217 (1989). DOI: 10.1016/0032-3861(89)90107-9

[4] Hourston D. J., Lane J. M.: The toughening of epoxy resins with thermoplastics: 1 . Trifunctional epoxy resinpolyetherimide blends. Polymer, 33, 1379-1383 (1992). DOI: 10.1016/0032-3861(92)90110-I

[5] Pascault J-P., Sautereau H., Williams R. J. J., Verdu J.: Thermosetting polymers. Marcel Dekker, New York (2002).

DOI: $10.1201 / 9780203908402$

[6] Tanaka H., Lovinger A. J., Davis D. D.: Pattern evolution caused by dynamic coupling between wetting and phase separation in binary liquid mixture containing glass particles. Physical Review Letters, 72, 25812584 (1994).

DOI: 10.1103/PhysRevLett.72.2581

[7] Ginzburg V. V., Qiu F., Paniconi M., Peng G., Jasnow D., Balazs A. C.: Simulation of hard particles in a phase-separating binary mixture. Physical Review Letters, 82, 4026-4029 (1999).

DOI: 10.1103/PhysRevLett.82.4026
[8] Suppa D., Kuksenok O., Balazs A. C., Yeomans J. M.: Phase separation of a binary fluid in the presence of immobile particles: A lattice Boltzmann approach. Journal of Chemical Physics, 116, 6305-6310 (2002). DOI: 10.1063/1.1460863

[9] Nesterov A. E., Lipatov Y. S., Horichko V. S., Ignatova T. D.: Effect of filler on kinetics and energy of activation of phase separation in poly(methyl methacrylate)/ poly(vinyl acetate) blend. Macromolecular Chemistry and Physics, 199, 2609-2612 (1998).

DOI: 10.1002/(SICI)1521-3935(19981101)199:11< 2609::AID-MACP2609>3.0.CO;2-Z

[10] Nesterov A. E., Lipatov Y. S., Horichko V. V., Gritsenko O. T.: Filler effects on the compatibility and phase separation kinetics of poly(vinyl acetate)-poly (methyl methacrylate) mixtures. Polymer, 33, 619622 (1992).

DOI: 10.1016/0032-3861(92)90740-N

[11] Lipatov Y. S., Nesterov A. E., Ignatova T. D., Nesterov D. A.: Effect of polymer-filler surface interactions on the phase separation in polymer blends. Polymer, 43, 875-880 (2002).

DOI: $10.1016 / \mathrm{S} 0032-3861(01) 00632-2$

[12] Yurekli K., Karim A., Amis E. J., Krishnamoorti R.: Influence of layered silicates on the phase-separated morphology of PS-PVME blends. Macromolecules, 36, 7256-7267 (2003).

DOI: $10.1021 / \mathrm{ma} 0207551$

[13] Kelnar I., Rotrekl J., Kotek J., Kaprálková L.: Effect of montmorillonite modification on the behaviour of polyamide/polystyrene blends. Polymer International, 57, 1281-1286 (2008). DOI: $10.1002 /$ pi.2475

[14] Kelnar I., Rotrekl J., Kotek J., Kaprálková L., Hromádková J.: Effect of montmorillonite on structure and properties of nanocomposite with PA6/PS/elastomer matrix. European Polymer Journal, 45, 27602766 (2009).

DOI: 10.1016/j.eurpolymj.2009.06.024

[15] Mabrouk K. E., Bousmina M.: Phase separation of polystyrene/poly(vinylmethylether)/organoclay nanocomposites. Journal of Nanoscience and Nanotechnology, 6, 472-482 (2006). DOI: $10.1166 /$ jnn.2006.093

[16] El-Mabrouk K., Vandreuil S., Zeghloul A., Bousmina M.: Effect of shear on phase-separation in polystyrene/ poly(vinyl methyl ether)/organoclay nanocomposites. Journal of Nanoscience and Nanotechnology, 8, 18951900 (2008). DOI: $10.1166 /$ jnn.2008.0191895

[17] Balazs A. C., Ginzburg V. V., Qiu F., Peng G., Jasnow D.: Multi-scale model for binary mixtures containing nanoscopic particles. Journal of Physical Chemistry B, 104, 3411-3422 (2000). DOI: $10.1021 / j p 993356+$ 
[18] Araki T., Tanaka H.: Dynamic depletion attraction between colloids suspended in a phase-separating binary liquid mixture. Journal of Physics: Condensed Matter, 20, 072101/1-072101/6 (2008). DOI: $\underline{10.1088 / 0953-8984 / 20 / 7 / 072101}$

[19] Lee S-H., Kim M-J., Park H.: Characteristics of cotton fabrics treated with epichlorohydrin and chitosan. Journal of Applied Polymer Science, 117, 623-628 (2010).

DOI: 10.1002/app.31351

[20] Bao S., Shen S., Liang G., Zhai H., Xu W., He P.: Curing behavior of epoxy resin/tung oil anhydride exfoliated nanocomposite by differential scanning calorimetry. Journal of Applied Polymer Science, 92, 3822-3829 (2004).

DOI: 10.1002/app.20398

[21] Kelnar I., Rotrekl J., Kaprálková L., Hromádková J., Strachota A.: Effect of amine-terminated butadieneacrylonitrile/clay combinations on the structure and properties of epoxy nanocomposites. Journal of Applied Polymer Science, 125, 3477-3483 (2012).

DOI: 10.1002/app.36696

[22] Hodgkin J. H., Simon G. P., Varley R. J.: Thermoplastic toughening of epoxy resins: A critical review. Polymers for Advanced Technologies, 9, 3-30 (1998).

DOI: 10.1002/(SICI)1099-1581(199801)9:1<3::AID-

$$
\text { PAT727>3.0.CO;2-I }
$$

[23] Inoue T.: Reaction-induced phase decomposition in polymer blends. Progress in Polymer Science, 20, 119153 (1995).

DOI: 10.1016/0079-6700(94)00032-W

[24] Tanaka H.: Appearance of a moving droplet phase and unusual networklike or spongelike patterns in a phaseseparating polymer solution with a double-well-shaped phase diagram. Macromolecules, 25, 6377-6380 (1992). DOI: $10.1021 / \mathrm{ma} 00049 \mathrm{a} 042$

[25] Araki T., Tanaka H.: Three-dimensional numerical simulations of viscoelastic phase separation: Morphological characteristics. Macromolecules, 34, 1953-1963 (2001).

DOI: $10.1021 / \mathrm{ma} 001569 \mathrm{n}$

[26] Ishii Y., Ryan A. J.: Processing of poly(2,6-dimethyl1,4-phenylene ether) with epoxy resin. 1. Reactioninduced phase separation. Macromolecules, 33, 158166 (2000)

DOI: $10.1021 / \mathrm{ma} 990837 \mathrm{i}$

[27] Cicala G., Mamo A., Recca G., Restuccia C. L.: Study on epoxy/thermoplastic blends based on the addition of a novel aromatic block copolymer. Polymer Engineering and Science, 47, 2027-2033 (2007). DOI: $10.1002 /$ pen.20915

[28] Rotrekl J., Matějka L., Kaprálkova L., Zhigunov A., Hromádková J., Kelnar I.: Epoxy/PCL nanocomposites: Effect of layered silicate on structure and behavior. Express Polymer Letters, 6, 975-986 (2012). DOI: $10.3144 /$ expresspolymlett.2012.103
[29] Kratochvíl J., Rotrekl J., Kaprálková L., Hromádková J., Kelnar I.: Epoxy/poly(c-caprolactone) nanocomposites: Effect of transformations of structure on crystallization. Journal of Applied Polymer Science, in press, (2013).

DOI: 10.1002/app.39536

[30] Chambon F., Winter H. H.: Linear viscoelasticity at the gel point of a crosslinking PDMS with imbalanced stoichiometry. Journal of Rheology, 31, 683-697 (1987). DOI: $10.1122 / 1.549955$

[31] Lan T., Karivatna P. D., Pinnavaia T. J.: Mechanism of clay tactoid exfoliation in epoxy-clay nanocomposites. Chemistry of Materials, 7, 2144-2150 (1995).

DOI: $10.1021 / \mathrm{cm} 00059 \mathrm{a} 023$

[32] Le Pluart L., Duchet J., Sautereau H.: Epoxy/montmorillonite nanocomposites: Influence of organophilic treatment on reactivity, morphology and fracture properties. Polymer, 46, 12267-12278 (2005).

DOI: $10.1016 /$ j.polymer.2005.10.089

[33] Ton-That M-T., Ngo T-D., Ding P., Fang G., Cole K. C., Hoa S. V.: Epoxy nanocomposites: Analysis and kinetics of cure. Polymer Engineering and Science, 44, 1132-1141 (2004).

DOI: $10.1002 /$ pen.20106

[34] Lan T., Kaviratna P. D., Pinnavaia T. J.: Epoxy selfpolymerization in smectite clays. Journal of Physics and Chemistry of Solids, 57, 1005-1010 (1996). DOI: 10.1016/0022-3697(95)00388-6

[35] Ishii Y., Ryan A. J.: Processing of poly(2,6-dimethyl1,4-phenylene ether) with epoxy resin. 2. Gelation mechanism. Macromolecules, 33, 167-176 (2000).

DOI: $10.1021 / \mathrm{ma} 990838 \mathrm{a}$

[36] Cicala G., La Spina R., Recca A., Sturiale S.: Influence of copolymer's end groups and molecular weights on the rheological and thermomechanical properties of blends of novel thermoplastic copolymers and epoxy resins. Journal of Applied Polymer Science, 101, 250257 (2006) DOI: $10.1002 / a p p .23275$

[37] Ginzburg V. V.: Influence of nanoparticles on miscibility of polymer blends. A simple theory. Macromolecules, 38, 2362-2367 (2005).

DOI: $10.1021 / \mathrm{ma} 0482821$

[38] Shi W., Yang J., Liu W., Zhang L., Han C. C.: Anomalous phase separation dynamics under asymmetric viscoelastic effect: Where fluidic and elastic properties meet. Macromolecules, 46, 2516-2520 (2013). DOI: $10.1021 / \mathrm{ma} 400032 \mathrm{w}$

[39] Kelnar I., Rotrek1 J., Kapralková L., Hromádková J.: Effect of poly(oxyalkylene)amines on structure and properties of epoxide nanocomposites. Journal of Applied Polymer Science, 125, 2755-2763 (2012). DOI: 10.1002/app.36604

[40] Mezzenga R., Luciani A., Månson J-A. E.: Phase separation and gelation of epoxy resin/hyperbranched polymer blends. Polymer Engineering and Science, 42, 249-257 (2002).

DOI: $10.1002 /$ pen.10945 